Journal of Machine Engineering, 2020, Vol. 20, No. 2, 86-93

ISSN 1895-7595 (Print) ISSN 2391-8071 (Online)

Received: 20 November 2019 / Accepted: 10 March 2020 / Published online: 24 June 2020

micro-milling, SLM process,

CoCr alloys

\author{
Marta KRAWCZYK ${ }^{1 *}$, Bartosz POWALKA ${ }^{1}$ \\ Marcin MATUSZAK ${ }^{2}$, Sebastian FRYSKA ${ }^{1}$ \\ Dariusz GRZESIAK ${ }^{1}$, Pawel FIGIEL ${ }^{1}$
}

\title{
THE ROLE OF THE ADDITIVE MANUFACTURING PROCESS PARAMETERS IN THE SHAPING OF THE SURFACE GEOMETRIC STRUCTURE DURING MICRO-MILLING
}

\begin{abstract}
The article presents the results of measurements of the geometric structure of the surface after micro end-milling. In the experiments, coated monolithic super micrograin cemented carbide micro end mills with 2 flutes were employed. The machined parts were additively made of $\mathrm{CoCr}$ alloy using Selective Laser Melting technology (SLM). Analyzed variables were the volumetric density of energy supplied by the laser during the SLM process and the feed rate during micro-milling. The results showed a strong influence of SLM process parameters on the surface roughness, which, according to the authors, results from the significant variability of the mechanical properties of the material as a function of the volumetric density of energy supplied during melting.
\end{abstract}

\section{INTRODUCTION}

Cobalt-chromium alloys are characterized by good wear resistance, corrosion resistance, creep strength and heat resistance [1-8]. They are used in the nuclear and aviation industries as well as in the production of gas turbine components. Due to the possibility of creating passive oxide layers on the surface, cobalt and chromium alloys are used for implantable medical devices, such as the orthopaedic knee, shoulder, hip prostheses, and bone fracture connectors. Besides, they are widely used in implantology and dental prosthetics [2-6, 9-12]. The above applications require precise mapping of the shape and low surface roughness to ensure in vivo longevity $[3,6-8,12,13]$. To meet dimensional and shape requirements of products in medical applications, as well as to ensure their integrity, various surface treatment methods are used (turning, milling, polishing, electro-erosion machining) $[1,3,6]$.

In dental applications, $\mathrm{CoCr}$ alloy products are most often made with lost wax casting techniques (LWC) [9-11, 14]. However, this conventional method has disadvantages such as wax pattern distortion, irregularities in the cast metal, complicated procedures and time-

\footnotetext{
${ }^{1}$ West Pomeranian University of Technology Szczecin, Department of Mechanical Engineering and Mechatronics, Szczecin, Poland

${ }^{2}$ Maritime University of Szczecin, Mechanical Department, Szczecin, Poland

*E-mail: mkrawczyk@zut.edu.pl https://doi.org/10.36897/jme/119673
} 
consuming processing. Some of the disadvantages of LWC have been eliminated by using advanced production techniques, such as CNC machining [4, 7, 9-11, 14]. Unfortunately, the subtractive machining of $\mathrm{CoCr}$ alloys has several problems, mainly the low cutting tools life and low machining efficiency, as well as the difficulty in obtaining high-quality machined surfaces. These problems are the result of the low thermal conductivity of the material, its susceptibility to high deformation, high hardness at elevated temperatures and high wear resistance $[1,6,7,11]$. Also, subtractive manufacturing techniques are characterized by a high percentage of waste material, the amount of which can reach $90 \%$ of the starting material $[9,11,14,15]$. Recently, additive manufacturing techniques, mainly SLM/DMLS (Selective Laser Melting/Direct Metal Laser Sintering), which enable the production of products through the layered building from powdered metal per the 3D model, are becoming an alternative to the above methods $[9,11,14,15]$.

These techniques have a rather significant disadvantage - the objects produced using them are characterized by high surface roughness and insufficient dimensional and shape accuracy as well as good surface integrity $[9-12,14,15]$. In dentistry, proper surface finish and matching of mating elements are crucial to minimizing plaque build-up and food accumulation, as this may lead to oral health deterioration [2, 9-11, 14]. Therefore, in-depth research into methods to improve the geometric characteristics of dentures and implants made of dental alloys is key [2, 9-11]. In dental applications, due to the small size of the obtained parts of the objects, micro-milling processes, which are widely used for the production of miniature parts and components of high quality, can be used [16-18]. Although the research on the influence of micro-milling on the geometric structure of the surface (SGS) was conducted by other researchers [16-20], the work presented is, according to the best knowledge of the authors, the first relating to cobalt-chromium alloys.

The presented work focuses on the SGS assessment of cobalt-chromium alloys obtained by the additive manufacturing method SLM, as well as the study of the influence of both SLM and micro-milling process parameters on SGS parameters.

\section{EXPERIMENTAL DETAILS}

Test samples were made of cobalt-chromium alloy (ASTM F75) using the Selective Laser Melting (SLM) additive manufacturing technique. The process was carried out on the REALIZER II 250 (MCP-HEK-Realizer) device equipped with a $100 \mathrm{~W} \mathrm{Nd:} \mathrm{YAG} \mathrm{laser.}$ A series of $10 \times 10 \times 10 \mathrm{~mm}$ samples were prepared. The SLM process parameters are summarized in Table 1.

The process was carried out at constant values of laser power $(P)$, layer thickness $(d)$ and distance of the laser paths $(h)$. The main variable was the laser exposure time at a single point $(t)$, and the derivative variables were the scanning speed $(V)$ and the volumetric energy density $(E)$.

The produced samples were subjected to a micro-milling process. In the carried out experiments, the monolithic super micro-grain cemented carbide micro end mills with coating were employed. The tools had the following geometry: diameter $D=1 \mathrm{~mm}$, number of teeth $z=2$, orthogonal rake angle $\gamma_{o}=-3^{\circ}$, orthogonal flank angle $\alpha_{o}=14^{\circ}$ and helix angle $\lambda_{s}=30^{\circ}$. 
The full slot micro-milling tests were conducted without the application of cutting fluids. The micro-milling parameters applied in experiments are presented in Table 2.

Table 1. The selective laser melting process parameters

\begin{tabular}{|c|c|c|c|c|c|}
\hline$P[\mathrm{~W}]$ & $t[\mathrm{~s}]$ & $V[\mathrm{~mm} / \mathrm{s}]$ & $h[\mathrm{~mm}]$ & $d[\mathrm{~mm}]$ & $E\left[\mathrm{~J} / \mathrm{mm}^{3}\right]$ \\
\hline 100 & 0.000144 & 555 & 0.12 & 0.03 & 50 \\
\hline 100 & 0.000216 & 370 & 0.12 & 0.03 & 75 \\
\hline 100 & 0.000286 & 280 & 0.12 & 0.03 & 100 \\
\hline
\end{tabular}

Table 2. The milling parameters applied in experiments

\begin{tabular}{|c|c|c|c|c|}
\hline$a_{\mathrm{e}}[\mathrm{mm}]$ & $f_{\mathrm{z}}[\mu \mathrm{m} /$ tooth $]$ & $a_{p}[\mu \mathrm{m}]$ & $v_{c}[\mathrm{~m} / \mathrm{min}]$ & $n[\mathrm{rev} / \mathrm{min}]$ \\
\hline 1 & $1,2,3,4,7$ & 20,40 & 23.9 & 7600 \\
\hline
\end{tabular}

The experiments were carried out on a prototype milling center with the 3 numerically controlled axes and maximal rotational speed of $100000 \mathrm{rev} / \mathrm{min}$. The milling center has workspace dimensions of $50 \times 50 \times 50 \mathrm{~mm}$. It is equipped with linear stages that have $2.5 \mu \mathrm{m}$ accuracy in the $X$ direction, $4 \mu \mathrm{m}$ accuracy in the $Y$ direction and $3 \mu \mathrm{m}$ accuracy in the $Z$ direction. All axes have $0.1 \mu \mathrm{m}$ repeatability. The machine body is made from granite to avoid thermal deformations and minimize vibrations. The milling center and experimental set-up are presented in Fig. 1.

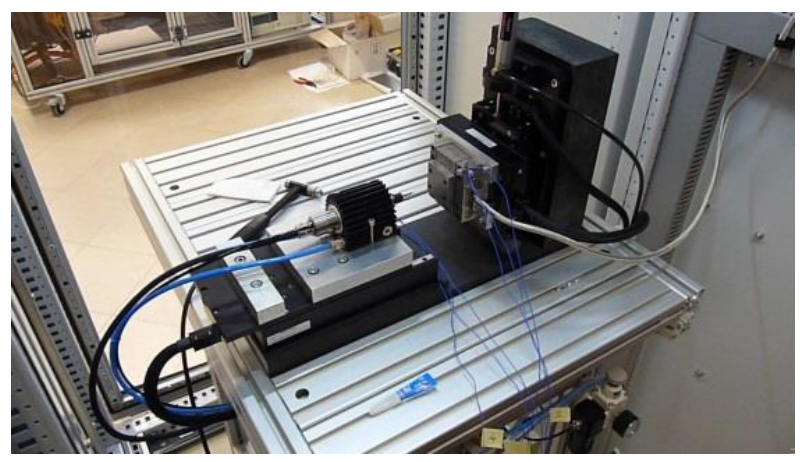

Fig. 1. Milling center and experimental set-up

Atomic Force Microscope (AFM) (MultiMode, Nanoscope IV, Bruker) was used to investigate surface topography. The contact mode was used with the scan size area $100 \times 100 \mu \mathrm{m}$. Both height and deflection image was captured. To generate the surface 3D view the height image was used. Measurements were taken at two locations: in the middle of the groove and at the distance of $50 \mu \mathrm{m}$ from the wall of the groove (see Fig. 2). The sample measured surface is shown in Fig. 3.

The measured heights were used to compute surface roughness parameters such as $S a$, $S q, S s k, S k u, S p, S v$, and $S z$. Three factors, depth of cut $\left(a_{p}\right)$, feed $(f)$ and volumetric energy density $(E)$ were considered. The influence of these factors on surface roughness parameters 
was studied using analysis of variance (ANOVA). The $F$-ratios and corresponding $P$-values were computed for all three main factors and their interaction. The analysis of variance was performed separately for two locations of the measurements.

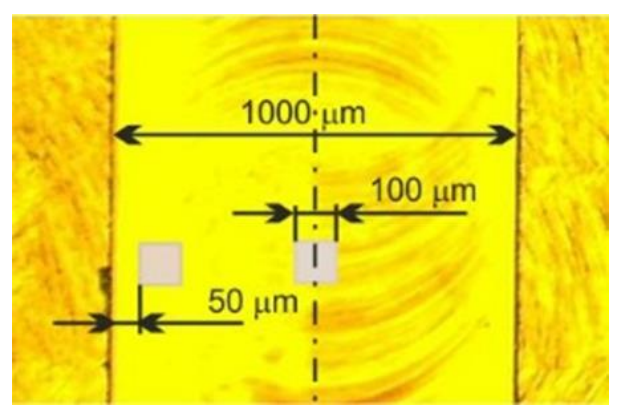

Fig. 2. Locations of the measurements areas

\section{RESULTS AND DISCUSSION}

The results of the ANOVA are shown in Table 3. The influence of the depth of cut $\left(a_{p}\right)$, feed $(f)$ and volumetric energy density $(E)$ on the SGS parameters such as $S a, S q, S s k, S k u$, $S p, S v$, and $S z$ are presented separately for two locations of the measurements: middle of the grove and $50 \mu \mathrm{m}$ from the wall.

Factors that have the greatest impact on individual SGS parameters have been marked. In almost every case the most important was volumetric energy density $(E)$ and feed $\left(f_{z}\right)$. Only in one case $(S v)$ an additional significant effect of $a_{p}$ was observed. This allows us to conclude that SGS properties are generated already at the stage of sample preparation, while the machining processes affect it later. Interaction factors have been removed due to their insignificant influence on surface roughness parameters.

The dependence of the $S s k$ parameter on volumetric energy density $(E)$ is shown in Fig. 3. Analyzing the graph above, it can be seen that as the volumetric energy density increases, the distribution type of the $S s k$ parameter changes. For the lowest value $E$ is asymmetric right-sided, for $75 \mathrm{~J}$ it is asymmetrical left-sided and this is also the case for $E$ at the highest level.

It is worth adding that the $S s k$ parameter provides information on surface asymmetry, while the value of the $S s k$ parameter indicates the predominance of peaks on the surface $(S s k>0)$ or valleys $(S s k<0)$. For $E$ values at 50 and $75 \mathrm{~J}$, it can be seen that the surface roughness parameter $S s k$ is positive. This means that most of the material is located near the valleys. For $E$ of $100 \mathrm{~J}$, the surface roughness parameter $S s k$ is negative, which means that most of the material is located near the peaks (see Fig. 4). The above effect may be caused by higher porosity or the presence of unmelted $\mathrm{CoCr}$ powder grains for lower $E$. Given the quartile range, the larger values for extreme $E$ values (50 and $100 \mathrm{~J}$ ) are visible, which indicates greater statistical diversity.

Figure 5 presents the dependence of the $S v$ parameter on the depth of cut $\left(a_{p}\right)$ and Fig. 6 shows the $3 \mathrm{D}$ view of the exemplary machined surface. 
Table 3. The results of the ANOVA

\begin{tabular}{|c|c|c|c|c|c|c|c|c|}
\hline & \multicolumn{4}{|c|}{ Middle of the groove } & \multicolumn{4}{|c|}{$50 \mu \mathrm{m}$ from the wall } \\
\hline & & 'd.f.' & 'Mean Sq.' & 'Prob $>F^{\prime}$ & & 'd.f.' & 'Mean Sq.' & 'Prob $>F^{\prime}$ \\
\hline \multirow{5}{*}{$S a$} & $a_{p}$ & 1 & 0.000304 & 0.102345 & $a_{p}$ & 1 & $2.42 \mathrm{E}-05$ & 0.6277257 \\
\hline & $f_{z}$ & 4 & 0.007183 & 0.000263 & $f_{z}$ & 4 & 0.0024478 & 0.00352 \\
\hline & $E$ & 2 & 0.000792 & 0.021568 & $E$ & 2 & 0.0005496 & 0.0587061 \\
\hline & Error & 4 & $6.82 \mathrm{E}-05$ & & Error & 4 & 8.79E-05 & \\
\hline & Total & 23 & & & Total & 23 & & \\
\hline \multirow{5}{*}{$S q$} & $a_{p}$ & 1 & 0.000401 & 0.116571 & $a_{p}$ & 1 & $2.83 \mathrm{E}-05$ & 0.6783805 \\
\hline & $f_{z}$ & 4 & 0.010015 & 0.000295 & $f_{z}$ & 4 & 0.0034929 & 0.0044729 \\
\hline & $E$ & 2 & 0.000862 & 0.03588 & $E$ & 2 & 0.00077 & 0.0727794 \\
\hline & Error & 4 & 0.000101 & & Error & 4 & 0.0001422 & \\
\hline & Total & 23 & & & Total & 23 & & \\
\hline \multirow{5}{*}{$S k u$} & $a_{p}$ & 1 & 0.0168017 & 0.707418 & $a_{p}$ & 1 & 3.0710316 & 0.4863388 \\
\hline & $f_{z}$ & 4 & 0.2407617 & 0.2164178 & $f_{z}$ & 4 & 3.7043225 & 0.6270225 \\
\hline & $E$ & 2 & 0.4405585 & 0.1019778 & $E$ & 2 & 3.4703224 & 0.5639741 \\
\hline & Error & 4 & 0.1033466 & & Error & 4 & 5.2328569 & \\
\hline & Total & 23 & & & Total & 23 & & \\
\hline \multirow{5}{*}{ Ssk } & $a_{p}$ & 1 & 0.0742609 & 0.3297774 & $a_{p}$ & 1 & 0.1908789 & 0.3530126 \\
\hline & $f_{z}$ & 4 & 0.01376 & 0.9095559 & $f_{z}$ & 4 & 0.1702284 & 0.5064226 \\
\hline & $E$ & 2 & 0.4248154 & 0.0490526 & $E$ & 2 & 0.2447789 & 0.3432843 \\
\hline & Error & 4 & 0.0604269 & & Error & 4 & 0.1731692 & \\
\hline & Total & 23 & & & Total & 23 & & \\
\hline \multirow{5}{*}{$S p$} & $a_{p}$ & 1 & 0.0055922 & 0.2918344 & $a_{p}$ & 1 & 0.0005158 & \\
\hline & $f_{z}$ & 4 & 0.0397583 & 0.0215054 & $f_{z}$ & 4 & 0.014589 & \\
\hline & $E$ & 2 & 0.0097302 & 0.1923248 & $E$ & 2 & 0.0109408 & \\
\hline & Error & 4 & 0.0038001 & & Error & 4 & 0.0039888 & \\
\hline & Total & 23 & & & Total & 23 & & \\
\hline \multirow{5}{*}{$S v$} & $a_{p}$ & 1 & 0.0061984 & 0.0436147 & $a_{p}$ & 1 & $1.21 \mathrm{E}-05$ & 0.8771339 \\
\hline & $f_{z}$ & 4 & 0.0412362 & 0.0009002 & $f_{z}$ & 4 & 0.0170275 & 0.0019342 \\
\hline & $E$ & 2 & 0.0046881 & 0.0565395 & $E$ & 2 & 0.0058332 & 0.0176987 \\
\hline & Error & 4 & 0.0007312 & & Error & 4 & 0.0004476 & \\
\hline & Total & 23 & & & Total & 23 & & \\
\hline \multirow{5}{*}{$S_{z}$} & $a_{p}$ & 1 & 0.0235656 & 0.1173617 & $a_{p}$ & 1 & 0.0003696 & 0.8229353 \\
\hline & $f_{z}$ & 4 & 0.1610955 & 0.003712 & $f_{z}$ & 4 & 0.0594171 & 0.0270864 \\
\hline & $E$ & 2 & 0.0099343 & 0.2968948 & $E$ & 2 & 0.0287835 & 0.0963301 \\
\hline & Error & 4 & 0.0059468 & & Error & 4 & 0.0064771 & \\
\hline & Total & 23 & & & Total & 23 & & \\
\hline
\end{tabular}

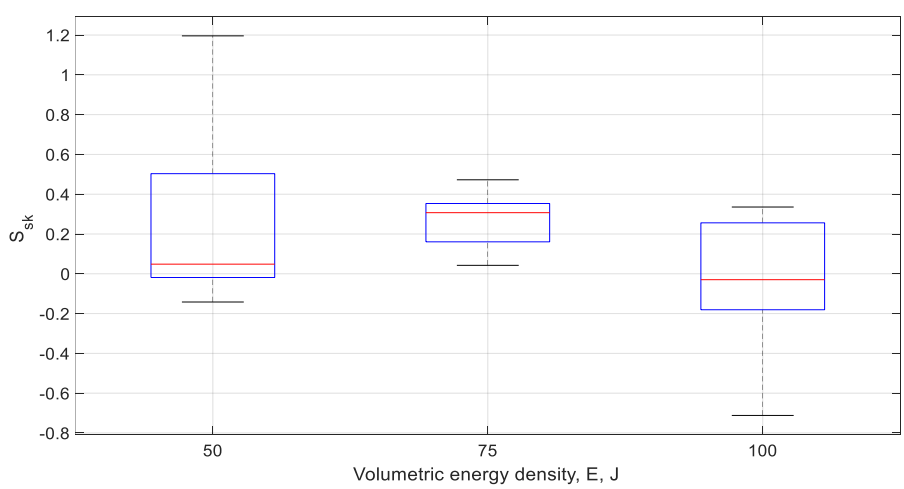

Fig. 3. Plots of the dependence of the $S s k$ parameter on volumetric energy density $(E)$ 


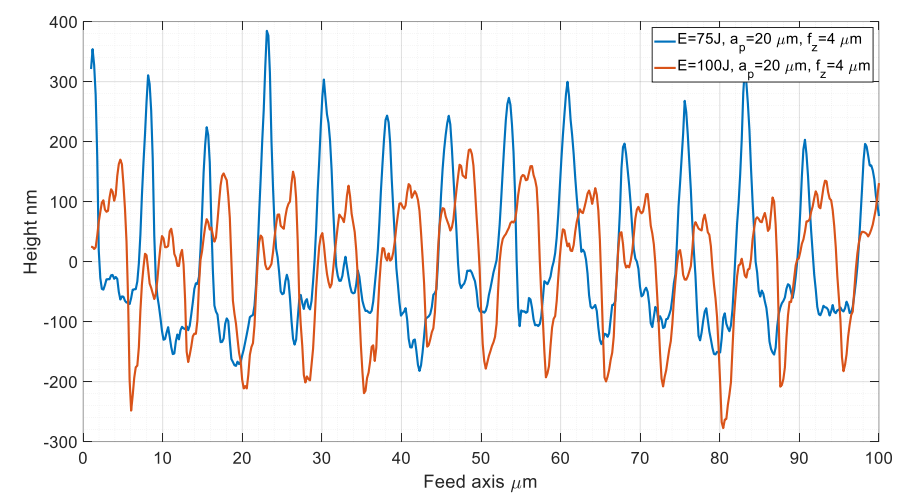

Fig. 4. Surface profiles obtained for different volumetric energy densities $(E)$

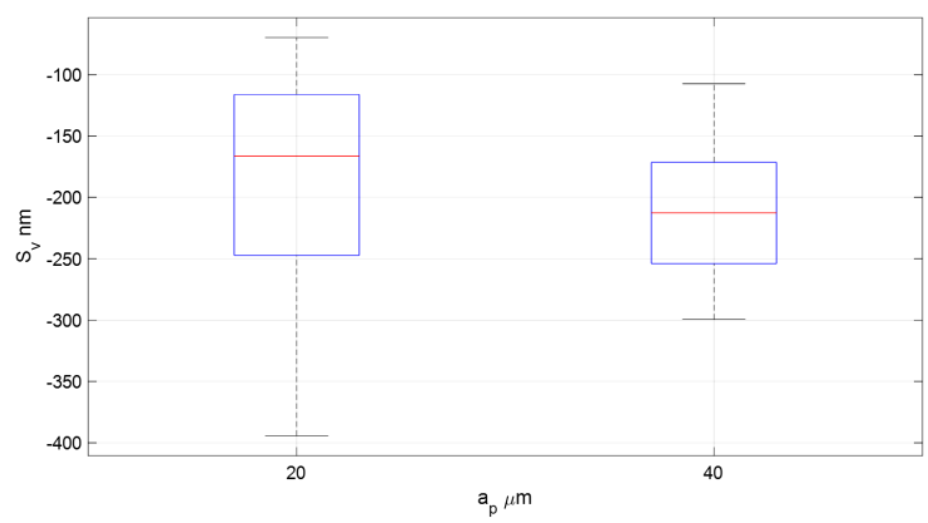

Fig. 5. Plots of the dependence of the $\mathrm{S} v$ parameter on the depth of cut $\left(a_{p}\right)$

$\mathrm{S}_{\mathrm{v}}$ is one of the functional parameters of the surface. Considering the depth of the lowest depression of the surface Sv depending on the feed, it can be stated that for the lower value of $a_{p}$ a higher $\mathrm{S}_{\mathrm{v}}$ was obtained. In both considered cases the distribution of the $S v$ parameter is asymmetrical (Figs. 5 and 6). However, for $a_{p}$ equal to $20 \mu \mathrm{m}$ it is left-sided and for $40 \mu \mathrm{m}$ right-sided. Considering the quartile range, it is higher for a lower depth of cut.

The obtained results are consistent with the literature data [7,21], which shows that in the case of $\mathrm{CoCr}$ alloys a higher variability of surface roughness parameters after treatment is observed than in the case of other biocompatible materials. The above results confirm, that proper parameters selection, both - SLM, and micro-machining, have an influence on the SGS parameters obtained during CoCr alloy machining and, potentially, allows their control.

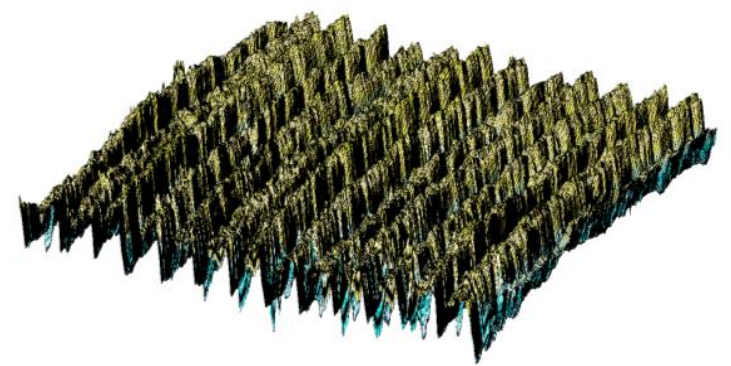

Fig. 6. 3D view of the machined surface (middle of the groove): $E=100 \mathrm{~J}, a_{p}=20 \mu \mathrm{m}, f_{z}=4 \mu \mathrm{m}$ 


\section{CONCLUSION}

Studies were carried out on the impact of SLM process parameters and micro-milling on the surface roughness of $\mathrm{CoCr}$ alloys. Analyzed variables were the volumetric density of energy $(E)$ supplied by the laser during the SLM process and the feed rate $\left(f_{z}\right)$ and depth of cut $\left(a_{p}\right)$ during micro-milling. The results of ANOVA analysis revealed that the roughness parameters in the considered cases are primarily influenced by $E$, and subsequently generated by the machining process. CoCr alloys are characterized by a wide variability of roughness parameters. The results of the research allow us to claim that by using properly selected parameters of the manufacturing process, the surface roughness can be controlled by reducing its variability towards narrower ranges. Research in this direction will continue.

\section{ACKNOWLEDGEMENTS}

We thank Jacek Zierke (Dental Service ZIERKE, Szczecin, Poland) for the cooperation and preparation of cast samples.

\section{REFERENCES}

[1] AYKUT S., BAGCI E., KENTLI A., YAZICIOĞLU O., 2007, Experimental Observation of Tool Wear, Cutting Forces and Chip Morphology in Face Milling of Cobalt Based Super-Alloy with Physical Vapour Deposition Coated and Uncoated Tool, Mater. Design, 28, 1880-1888.

[2] SHAO H., LI L., LIU L.J., ZHANG S.Z., 2013, Study on Machinability of a Stellite Alloy with Uncoated and Coated Carbide Tools in Turning, J. Manuf. Process., 15, 673-681.

[3] BARON S., AHEARNE E., 2018, Fundamental Mechanisms of Chip Formation in Orthogonal Cutting of Medical Grade Cobalt Chromium Alloy, (ASTM F75), CIRP-JMST, 23, 54-63.

[4] PASANG T., LEES S., TAKAHASHI M., FUJITA T., CONOR P., TANAKA K., KAMIYA O., 2017, Machining of Dental Alloys: Evaluating the Surface Finish of Laterally Milled Co-Cr-Mo Alloy, Procedia Manuf., 13, 5-12.

[5] AL JABBARI Y.S., 2014, Physico-Mechanical Properties and Prosthodontic Applications of Co-Cr Dental Alloys: A Review of the Literature, J. Adv. Prosthodont., 6, 138-45.

[6] ZAMAN H.A., SHARIF S., KIM D-W., IDRIS M.H., SUHAIMI M.A., TUMURKHUYAG Z., 2017, Machinability of Cobalt-based and Cobalt Chromium Molybdenum Alloys - A Review, Procedia Manuf., 11, 563-570.

[7] AXINTE D., GUO Y., LIAO Z., SHIH A.J., M'SAOUBI R., SUGITA N., 2019, Machining of Biocompatible Materials - Recent Advances, Ann-Manuf. Techn., 68, 629-652.

[8] SHOKRANI A., DHOKIA V., NEWMAN S.T., 2016, Cryogenic High Speed Machining of Cobalt Chromium Alloy, Procedia CIRP, 46, 404-407.

[9] TAMAC E., TOKSAVUL S., TOMAN M., 2014, Clinical Marginal and Internal Adaptation of CAD/CAM Milling, Laser Sintering, and Cast Metal Ceramic Crowns, J. Prosthet. Dent., 112/4, 909-913.

[10] ÖRTORP A., JÖNSSON D., MOUHSEN A., VULT VON STEYERN P., 2011, The Fit of Cobalt-Chromium Three-Unit Fixed Dental Prostheses Fabricated with Four Different Techniques: A Comparative in Vitro Study, Dent. Mater., 27, 356-363.

[11] KIM K.B., KIM W.C., KIM H.Y., KIM J.H., 2013, An Evaluation of Marginal Fit of Three-Unit Fixed Dental Prostheses Fabricated by Direct Metal Laser Sintering System, Dent. Mater., 29, e91-e96.

[12] BRAZEL E., HANLEY R., O'DONELL G.E., 2011, The Effects of Process Parameters on Spindle Power Consumption in Abrasive Machining of Cocr Alloy, J. Mach. Eng., 11/4, 59-69.

[13] ZENG S., BLUNT L., 2014, Experimental Investigation and Analytical Modelling of the Effects of Process Parameters on Material Removal Rate for Bonnet Polishing of Cobalt Chrome Alloy, Precis. Eng., 38, 348-355. 
[14] TAŞIN S., TURP I., BOZDAĞ E., SÜNBÜLOĞLU E., ÜŞÜMEZ A., 2019, Evaluation of Strain Distribution on an Edentulous Mandible Generated by Cobalt-Chromium Metal Alloy fixed Complete Dentures Fabricated with Different Techniques: An in Vitro Study, J. Prosthet. Dent., 122/1, 47-53.

[15] RUBERT S.C.G., CALAS M.D.M., SOSA J.B., ARBAS F.F., 2013, Analysis of Variability in the Manufacture of Cr-Co Fixed Partial Dentures by Geometric Comparison, Procedia Eng., 63, 481-488.

[16] HOJATI F., DANESHI A., SOLTANI B., AZARHOUSHANG B., BIERMANN D., 2019, Study on Machinability of Additively Manufactured and Conventional Titanium Alloys in Micro-Milling Process, Precis. Eng., https://doi.org/10.1016/j.precisioneng.2019.11.002.

[17] ZHANG X., YU T., ZHAO J., 2020, Surface Generation Modelling of Micro Milling Process With Stochastic Tool Wear, Precis. Eng., 61, 170-181.

[18] BERUVIDES G., CASTAÑO F., QUIZA R., HABER R.E., 2016, Surface Roughness Modelling and Optimization of Tungsten-Copper Alloys in Micro-Milling Processes, Measurement, 86, 246-252.

[19] AHMADIA M., KARPATA Y., ACARD O., KALAY Y.E., 2018, Microstructure Effects on Process Outputs in Micro Scale Milling of Heat Treated Ti ${ }_{6} A_{4}$ V Titanium Alloys, J. Mater. Process. Techol., 252, 333-347.

[20] CHENG J., XIAO Y., LIU Q., YANG H., ZHAO L., CHEN M., TAN J., LIAO W., CHEN J., YUAN X., 2018, Effect of Surface Scallop Tool Marks Generated in Micro-Milling Repairing Process on the Optical Performance of Potassium Dihydrogen Phosphate Crystal, Mater. Design., 157, 447-456.

[21] ABELlÁN-NEBOT J.V., SILLER H.R., VILA C., RODRIGUEZ A., 2012, An Experimental Study of Process Variables in Turning Operations of Ti-6Al-4V and Cr-Co Spherical Prostheses, Int. J. Adv. Manuf. Tech., 63/9-12, 887-902. 